\title{
Analysis of a Multi-Flap Control System for a Swashplateless Rotor
}

\author{
Martin K. Sekula \\ NASA Langley Research Center \\ Hampton, Virginia
}

\author{
Matthew L. Wilbur \\ U.S. Army Research Laboratory \\ Hampton, Virginia
}

\begin{abstract}
An analytical study was conducted examining the feasibility of a swashplateless rotor controlled through two trailing edge flaps (TEF), where the cyclic and collective controls were provided by separate TEFs. This analysis included a parametric study examining the impact of various design parameters on TEF deflections. Blade pitch bearing stiffness; blade pitch index; and flap chord, span, location, and control function of the inboard and outboard flaps were systematically varied on a utility-class rotorcraft trimmed in steady level flight. Gradient-based optimizations minimizing flap deflections were performed to identify single- and two-TEF swashplateless rotor designs. Steady, forward and turning flight analyses suggest that a two-TEF swashplateless rotor where the outboard flap provides cyclic control and inboard flap provides collective control can reduce TEF deflection requirements without a significant impact on power, compared to a single-TEF swashplateless rotor design.
\end{abstract}

\section{Background}

Trailing Edge Flaps (TEFs) are viewed as a potential method for providing main rotor primary flight control in lieu of a traditional swashplate-based control system ${ }^{1}$. Although analytical studies have demonstrated the ability of TEFs to trim the main rotor of various weight class helicopters ${ }^{2-5}$, they have also identified a substantial technical challenge in the implementation of TEFs on flight vehicles: the inability of current stateof-the-art actuators to provide an adequate range of flap deflections that is required for trimmed flight throughout the typical helicopter flight regime ${ }^{4,6}$. Eliminating this deficiency in control authority has been the subject of multiple studies which have attempted to identify design solutions that minimize flap displacement requirements ${ }^{2,3,7}$. Although these efforts have analytically demonstrated substantial reductions in the required flap displacements through proper design choices (such as TEF size, radial location and blade root properties), there still exists a performance gap between TEF trim requirements and available control authority.

The present study investigates a different approach to bridging the gap between required and practical TEF deflections. To date, most studies examining the use of TEFs for primary flight control have focused on using a single TEF to provide both collective and cyclic control of each rotor blade. The present approach, presented in Figure 1, distributes the cyclic and collective components of flight control between separate aerodynamic devices. Several other uses of multiple TEFs have been investigated previously, but not for primary flight control. Some investigations examined

Presented at the American Helicopter Society 67th Annual Forum, Virginia Beach, VA, May 3-5, 2011. This is a work of the U.S.

Government and is not subject to copyright protection in the U.S. the merits of employing two TEFs for rotor vibration control $^{8-10}$. Kim et al have demonstrated blade loads reduction using two TEFs ${ }^{11}$ and recently Gagliardi and Barakos have examined the use of two TEFs to improve hover performance ${ }^{12}$.

Utilizing two separate flaps for cyclic and collective pitch control may reduce TEF deflections, thereby making a swashplateless rotor feasible using current actuator technology. In addition, the proposed approach provides the option of tailoring the TEF actuator designs to different requirements: (1) somewhat slower response but large static deflections for collective pitch control, and (2) large $1 /$ rev dynamic response for cyclic pitch control. Separating these two potentially conflicting requirements may pose a less challenging problem for actuator designers.

\section{Analytical Model}

A CAMRAD II $^{13}$ model of a utility-class helicopter in free-flight was developed to examine the applicability of trailing edge flaps as primary flight control devices. The general properties of this vehicle are provided in Table 1. Vehicle drag, including that of the main rotor hub, is modeled as an equivalent flat-plate whose drag acts at the vehicle center of gravity. The locations of all vehicle components are measured with respect to the main rotor hub, where the offsets are positive down and aft. The rotor blades have a rectangular planform with uniform properties. Since vibration and noise reduction is not the subject of this study, an articulated rotor with rigid blades is employed to examine the problem instead of a full aeroelastic model. Furthermore, a linearly varying inflow model is used in lieu of more sophisticated wake and computational fluid dynamics (CFD) models, permitting a larger array of design parameters to be studied in an efficient manner. The 


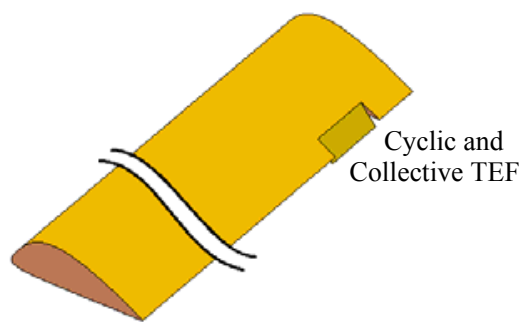

(a) Single-TEF control system for cyclic and collective control

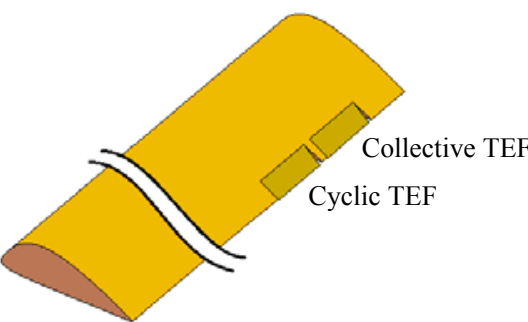

(b) Two-TEF control system: Outboard flap collective control; Inboard flap cyclic control

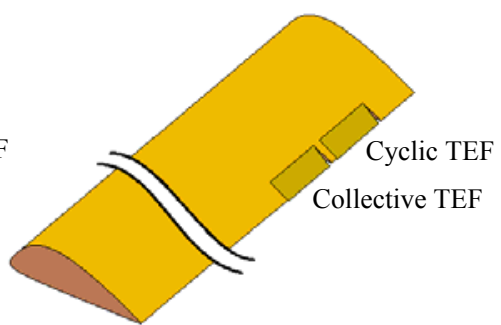

(c) Two-TEF control system: Outboard flap cyclic control; Inboard flap collective control

Figure 1. Single- and two-TEF swashplateless rotor flap function distribution.

forward flight speed range was likewise limited to $\mu=0.28$ to avoid persistent analysis convergence difficulties and the optimization restarts associated with such difficulties.

A combination of simple, first order approximations and table lookups is used to model aerodynamic loads produced by TEFs. Thin airfoil theory is employed to calculate the lift and pitching moment derivatives with respect to trailing edge flap deflection based on the flap chord $^{14}$. The drag due to flap deflections is modeled using modified C81 airfoil tables for the SC-1095 airfoil. The section drag coefficient values in these tables were adjusted to account for TEF deflections by adding CFD-derived incremental changes in the section drag originally calculated for a SC-1094 airfoil with a $20 \% \mathrm{TEF}^{15}$. These modifications were limited to \pm 10 degrees angle-of-attack range $(\alpha)$, TEF deflections $(\delta)$ between \pm 6 degrees, and Mach numbers (M) less than or equal to 1.0. Since CFD predictions were often not available for each particular $\alpha-\delta-\mathrm{M}$ combination used in the C81 tables, polynomial curve fits were used to interpolate and, for some extreme $\alpha-\delta$-M conditions, extrapolate to the required conditions. Unlike the lift and pitching moment coefficients, no effort was made to adjust the drag produced by the TEF to account for changes in chord length of various flap designs.

\section{Approach}

The two-TEF swashplateless rotor investigation is presented in three steps. An initial study is conducted using a gradient-based optimization method to identify an optimum design for a single-TEF control system. This study is used to develop methodologies for the analysis of the multiple-TEF control system and to gain insight into the TEF-based swashplateless rotor design problem. The second step examines the impact of various two-TEF swashplateless rotor design parameters on TEF deflections through a series of parametric studies. In the final step several candidate two-TEF swashplateless rotor designs are identified through a gradient-based optimization. The benefits of each design in terms of flap deflections, total vehicle power, and vehicle maneuverability are considered in selecting a final design. Likewise, the optimized two-TEF designs are compared to the optimized single-TEF design to determine whether this concept should be examined in further detail.

Table 1. Helicopter and rotor properties.

\begin{tabular}{|c|c|}
\hline \multicolumn{2}{|l|}{ Helicopter properties } \\
\hline Weight (lbs) & 16800 \\
\hline CG station $(\mathrm{ft})$ & 0 \\
\hline CG waterline (ft) & 5.82 \\
\hline Equivalent flat plate area $\left(\mathrm{ft}^{2}\right)$ & 22.56 \\
\hline Horizontal tail $\frac{d(L / Q)}{d \alpha}\left(\mathrm{ft}^{2} / \mathrm{rad}\right)$ & 269.4 \\
\hline Horizontal tail station $(\mathrm{ft})$ & 29.91 \\
\hline \multicolumn{2}{|l|}{ Main rotor properties" } \\
\hline Rotor radius (ft) & 26.8 \\
\hline Number of blades & 4 \\
\hline Solidity & 0.082 \\
\hline Tip Mach number & 0.649 \\
\hline Linear blade twist (deg) & -18 \\
\hline Root cutout $(\mathrm{r} / \mathrm{R})$ & 0.15 \\
\hline Flap frequency (/rev) & 1.03 \\
\hline Lag frequency (/rev) & 0.27 \\
\hline Elastic blade torsion frequency (/rev) & 3.79 \\
\hline \multicolumn{2}{|l|}{ Tail rotor properties } \\
\hline Rotor radius (ft) & 5.5 \\
\hline Number of blades & 4 \\
\hline Solidity & 0.188 \\
\hline Tail rotor station (ft) & 32.82 \\
\hline Rotor waterline $(\mathrm{ft})$ & -0.81 \\
\hline Rotational speed ratio & 5 \\
\hline
\end{tabular}




\section{Results}

\section{Optimal Single-TEF Design}

An optimization of a single-TEF swashplateless rotor design was conducted to minimize the magnitude of TEF deflection. Flap chord, flap radial location, pitch bearing stiffness, and blade pitch index were selected as inputs into a gradient-based optimization algorithm. Flap span was fixed at $0.15 \mathrm{R}$. The range of the design space is presented in Table 2. The objective function selected to identify the optimum TEF design is defined in Equation 1,

$$
\mathrm{J}_{1}=\max \left(\delta_{f}(\mu)\right)
$$

where $\delta_{\mathrm{f}}$ is the magnitude of the flap deflection as a function of advance ratio, $\mu$. This objective function identifies the maximum flap deflection across a range of flight speeds instead of at a single advance ratio. For this study, flight conditions ranging from hover to 0.28 advance ratio were examined.

As previously stated, the radial extent of the flap was not considered in this optimization study. During preliminary analyses, permitting unconstrained flap span resulted in unrealistically long flap designs so that flap deflections were minimized. If the total power was used as the objective function, the TEF design was biased towards very short flaps at inboard radial locations. This flap design resulted in extremely large TEF deflections that were exploited because the flap aerodynamic model does not include stall. Fixing the flap span avoided these issues and eliminated a constraint from the optimization effort.

Figure 2 presents the flap control settings as a function of advance ratio for several single-TEF swashplateless rotor designs. The two thicker line traces represent the flap deflection schedules for an initial design and an optimized design identified using the objective function specified in Equation 1. Also included in Figure 2 are four rotor designs optimized for specific flight speeds, advance ratios of $0.1,0.15,0.2$, or 0.25 . The flap deflections for each of these designs are represented by 'o' symbols at their corresponding design speeds. The design parameters for each rotor are provided in Table 3.

The flap deflection magnitude, $\delta_{\mathrm{f}}$, required to trim the rotor as a function of advance ratio is presented in Figure 2a. The optimum design maintains the flap deflections under 3.50 degrees within the $\mu \leq 0.28$ flight speed range. Since the optimization algorithm minimizes the maximum TEF deflections within this

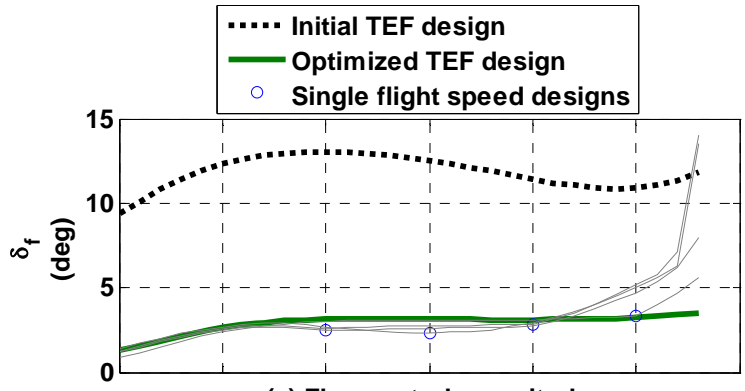

(a) Flap control magnitude

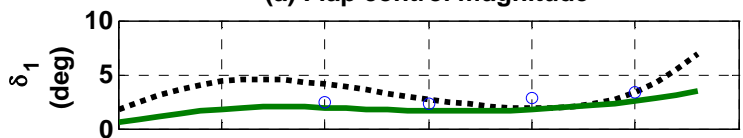

(b) Cyclic control amplitude

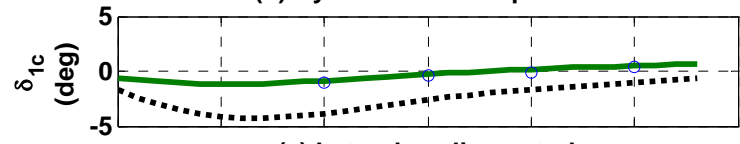

(c) Lateral cyclic control

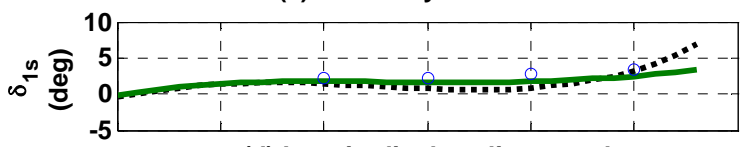

(d) Longitudinal cyclic control

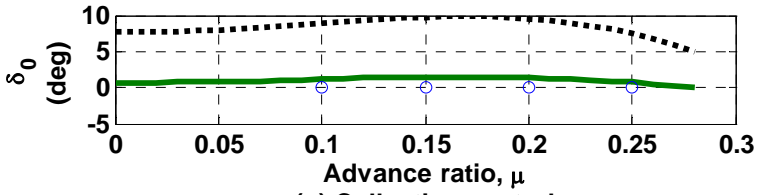

(e) Collective control

Figure 2. Flap deflections as a function of advance ratio for a single-TEF rotor.

Table 2. Range of design space.

\begin{tabular}{|l|c|c|}
\hline Parameter & Min. & Max. \\
\hline Blade pitch index $(\mathrm{deg})$ & 10 & 30 \\
\hline Pitch bearing stiffness $(\mathrm{ft}-\mathrm{lb} / \mathrm{rad})$ & 500 & 6000 \\
[torsion frequency] $(/ \mathrm{rev})$ & {$[1.15]$} & {$[2.46]$} \\
\hline Center of flap $\left(\mathrm{r}_{\mathrm{f}} / \mathrm{R}\right)$ & 0.575 & 0.925 \\
\hline Flap chord length $\left(\mathrm{c}_{\mathrm{f}} / \mathrm{c}\right)$ & 0.1 & 0.4 \\
\hline
\end{tabular}

Table 3. Swashplateless rotor design parameters.

\begin{tabular}{|l|c|c|c|c|}
\hline \multicolumn{1}{|c|}{ Design } & $\begin{array}{c}\text { Pitch } \\
\text { index } \\
(\mathrm{deg})\end{array}$ & $\begin{array}{c}\text { Torsion } \\
\text { frequency } \\
(/ \mathrm{rev})\end{array}$ & $\begin{array}{c}\text { Center of } \\
\text { flap } \\
(\mathrm{r} / \mathrm{R})\end{array}$ & $\begin{array}{c}\text { Flap chord } \\
\text { length } \\
\left(\mathrm{c}_{\mathrm{f}} / \mathrm{c}\right)\end{array}$ \\
\hline Initial & 20.00 & 1.94 & 0.838 & 0.1750 \\
\hline Optimized & 21.03 & 1.49 & 0.925 & 0.2314 \\
\hline$\mu=0.10$ & 16.90 & 1.55 & 0.925 & 0.2265 \\
\hline$\mu=0.15$ & 16.73 & 1.53 & 0.925 & 0.2359 \\
\hline$\mu=0.20$ & 16.42 & 1.58 & 0.925 & 0.2513 \\
\hline$\mu=0.25$ & 18.39 & 1.55 & 0.925 & 0.2589 \\
\hline
\end{tabular}

flight speed range, it can be surmised that the final optimized design is based on minimizing the TEF deflections at an advance ratio of 0.28 , the flight speed where the largest deflections occur. The rotor designs 
optimized for a single flight speed tend to exhibit slightly lower maximum flap deflections at their design speeds than the design optimized for the full range of flight conditions. These single flight speed designs, however, require larger flap deflections to trim the vehicle at the highest advance ratios (see gray lines in Fig. 2a), potentially limiting the flight envelope of the vehicle.

The full-flight-speed-range optimized design reduced the cyclic flap deflections compared to the initial design (Fig. 2b), although the reduction is much smaller than the total flap deflection change. This observation indicates that the majority of the reductions in TEF deflections come from the collective flap control. Analysis of the single-flight-speed designs also supports this conclusion. At their design speeds, these rotors always trimmed to larger cyclic flap deflections than the full-flight-speed-range optimized rotor (Fig. 2b) even though their maximum TEF deflection magnitudes $\left(\delta_{\mathrm{f}}\right)$ are smaller (Fig. 2a).

The collective control schedules are presented in Figure 2e. The full-flight-speed-range optimized rotor requires significantly lower collective controls compared to the initial design. The majority of the reduction comes from the large change in torsion frequency (pitch bearing stiffness) (see Table 3). The optimization resulted in positive $\delta_{0}$ throughout the entire flight envelope. Therefore, the TEF-produced pitching moment always reduces the blade pitch to the desired pitch angle, a control approach used on the Kaman $\mathrm{K}-\mathrm{MAX}$ and $\mathrm{SH}-2^{16}$.

Although the result is similar, the rationale behind Kaman's design is different than the present approach. Kaman's design maintains positive lift production from the flap, thereby offloading the rest of the blade. The optimization algorithm minimizes the maximum $\delta_{\mathrm{f}}$ by driving $\delta_{0}$ to zero degrees at the maximum flight speed considered in this optimization. In fact, the optimization algorithm always drove $\delta_{0}$ to zero at the advance ratio selected in the single flight speed optimizations (Fig. 2e).

\section{Two TEF Parametric Study}

The optimum design of the single-TEF swashplateless rotor identified in the preceding study was used to construct a model of a two-TEF swashplateless rotor. The parameters defining this new design are presented in Table 4. There are two primary differences between this new design and the single-TEF swashplateless rotor. The first is the addition of a second flap directly inboard of the original flap. The second difference is that the cyclic and collective control of the rotor are provided separately by the two TEFs. This separation of control responsibility results in two possible control schemes: inboard flap collective control and outboard flap cyclic control, and vice versa.

Using both control schemes, parametric studies were conducted examining the sensitivity of various TEF and blade root parameters on control requirements. The parameters consisted of inboard and outboard flap chord length, radial location, and span-wise length; pitch bearing stiffness; and blade pitch index angle. Each parameter was systematically varied in equal increments while the others were held constant. The range of variation of these parameters is presented in Table 5. It should be noted that, when necessary, some of the parameters were adjusted to prevent physical overlap of the two flaps.

Table 4. Baseline parameters for two-TEF swashplateless rotor design.

\begin{tabular}{|l|c|}
\hline Parameter & Value \\
\hline Blade pitch index $(\mathrm{deg})$ & 21.03 \\
\hline $\begin{array}{l}\text { Pitch bearing stiffness }(\mathrm{ft}-\mathrm{lb} / \mathrm{rad}) \\
\text { [torsion frequency] }(/ \mathrm{rev})\end{array}$ & 1517 \\
\hline \multicolumn{2}{|c|}{ Inboard flap } \\
\hline Span $\left(\mathrm{L}_{\mathrm{f}} / \mathrm{R}\right)$ & $0.19]$ \\
\hline Spanwise location of center $\left(\mathrm{r}_{\mathrm{f}} / \mathrm{R}\right)$ & 0.775 \\
\hline Flap chord length $\left(\mathrm{c}_{\mathrm{f}} / \mathrm{c}\right)$ & 0.231 \\
\hline \multicolumn{2}{|c|}{ Outboard flap } \\
\hline Span $\left(\mathrm{L}_{\mathrm{f}} / \mathrm{R}\right)$ & 0.15 \\
\hline Spanwise location of center $\left(\mathrm{r}_{\mathrm{f}} / \mathrm{R}\right)$ & 0.925 \\
\hline Flap chord length $\left(\mathrm{c}_{\mathrm{f}} / \mathrm{c}\right)$ & 0.231 \\
\hline
\end{tabular}

Table 5. Parameter variation for two-TEF parametric study.

\begin{tabular}{|c|c|c|}
\hline Parameter & Min & Max \\
\hline Blade pitch index (deg) & 10 & 30 \\
\hline $\begin{array}{l}\text { Pitch bearing stiffness (ft-lb/rad) } \\
\text { [torsion frequency] (/rev) }\end{array}$ & $\begin{array}{c}500 \\
{[1.15]}\end{array}$ & $\begin{array}{c}6000 \\
{[2.46]}\end{array}$ \\
\hline \multicolumn{3}{|l|}{ Inboard flap } \\
\hline $\operatorname{Span}\left(\mathrm{L}_{\mathrm{f}} / \mathrm{R}\right)^{*}$ & 0.1 & 0.35 \\
\hline $\begin{array}{l}\text { Spanwise location of } \\
\text { center }\left(r_{f} / R\right)\end{array}$ & 0.575 & 0.775 \\
\hline Flap chord length $\left(\mathrm{c}_{\mathrm{f}} / \mathrm{c}\right)$ & 0.1 & 0.4 \\
\hline \multicolumn{3}{|l|}{ Outboard flap } \\
\hline $\operatorname{Span}\left(L_{f} / R\right)^{\dagger}$ & 0.1 & 0.35 \\
\hline Spanwise location of center $\left(\mathrm{r}_{\mathrm{f}} / \mathrm{R}\right)^{*}$ & 0.725 & 0.925 \\
\hline Flap chord length $\left(\mathrm{c}_{\mathrm{f}} / \mathrm{c}\right)$ & 0.1 & 0.4 \\
\hline
\end{tabular}


In order to provide a comprehensive understanding of the effect of the various parameters on TEF deflections, each two-TEF model is trimmed across a range of advance ratios from hover to 0.28 . Trim schedules for designs where a single parameter is varied are plotted together, such as the effect of changes in pitch bearing stiffness on vehicle trim presented in Figure 3. Each curve represents the trim schedule for a specific design and the line color indicates the value of the modified design variable based on the color bar on the right of the plot. Thicker lines indicate the designs at the maximum and minimum limits of the varied parameter.

Throughout most of this parametric study, vehicle attitude exhibited a very limited sensitivity to many of the parameters examined. Therefore, fuselage pitch and roll trends are only presented for the cases where a notable effect is observed.

\section{Pitch bearing stiffness}

Pitch bearing stiffness, $\mathrm{K}_{\theta}$, directly affects the amount of blade pitch a TEF can produce. The effect of changes in pitch bearing stiffness on the trim schedule of a two-TEF swashplateless rotor is presented in Figure 3. For this set of designs, the inboard flap provides cyclic control and the outboard flap provides collective control. The pitch bearing stiffness is varied from 500 to $6000 \mathrm{ft}-\mathrm{lb} / \mathrm{rad}$, equivalent to a torsion frequency range of $1.15 / \mathrm{rev}$ to $2.49 / \mathrm{rev}$. For the minimum stiffness case the collective flap control angles are always negative, indicating that the flap has to produce a nose-up pitching moment to compensate for the blade's nose-down aerodynamic pitching moment (due to the cambered airfoil) and the propeller moment. As the pitch bearing stiffness increases, the collective flap deflections become more positive. Eventually, the pitch bearing becomes too stiff, limiting the advance ratio range where a trimmed solution is possible. In the present design the collective flap deflection can be minimized by employing a pitch bearing stiffness of 1000 to $1300 \mathrm{ft}-\mathrm{lb} / \mathrm{rad}$.

The cyclic control flap deflections, including the flap amplitude, are presented in Figures 3(b-d). The longitudinal cyclic control schedule, $\delta_{1 \mathrm{~s}}$, (Fig. $3 b$ ), becomes increasingly non-linear as the pitch bearing stiffness is increased. A stiffer pitch bearing results in a more negative $\delta_{1 \mathrm{c}}$, the lateral cyclic control (Fig. 3c), throughout the entire flight speed range examined. At advance ratios less than 0.23 , this change in $\delta_{1 \mathrm{c}}$ is the primary driver behind the increase in overall cyclic flap requirements (Fig. 3d). At higher advance ratios the impact of $\delta_{1 \mathrm{~s}}$ on cyclic flap deflections, $\delta_{1}$, becomes more pronounced.
Pitch bearing stiffness is one of the few parameters examined that had a noticeable effect on the vehicle attitude. The effect of changes in pitch bearing stiffness on fuselage pitch $\left(\alpha_{\mathrm{s}}\right)$ and roll $\left(\phi_{\mathrm{s}}\right)$ angles is presented in Figures 3(e-f). A stiffer pitch bearing results in a more nose-down and roll-right vehicle attitude.

A unique feature of this swashplateless rotor concept is that there are two possible control system configurations (depicted in Figures 1(b and c)). Figure 4 presents the effect of changes in pitch bearing stiffness on TEF controls for a configuration where the outboard flap provides cyclic control and the inboard flap provides collective control. This interchange of control function (from that presented in Fig. 3) between the two flaps has some profound effects on rotor trim. The first notable difference is the greater sensitivity of the collective flap control, $\delta_{0}$ (Fig. 4a), to changes in pitch bearing stiffness. Larger collective TEF deflections (compared

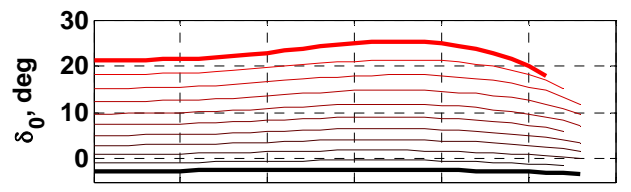

(a) Collective control

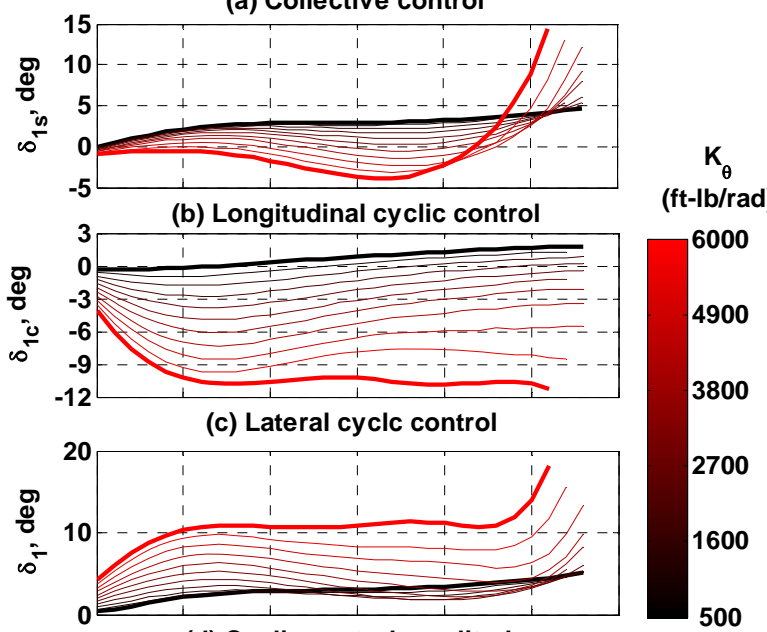

(d) Cyclic control amplitude

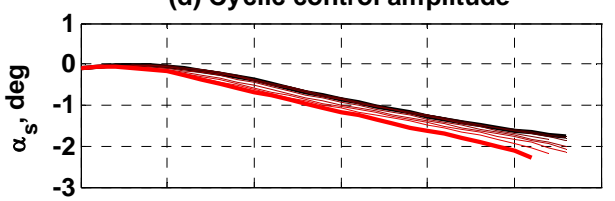

(e) Fuselage pitch

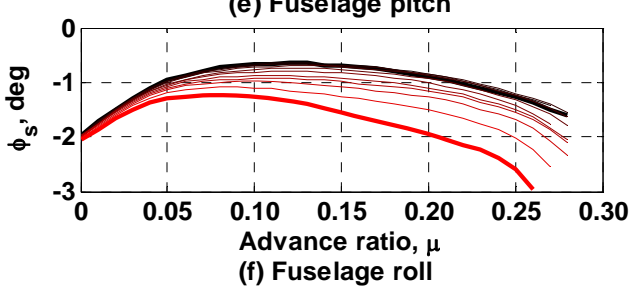

(f) Fuselage roll

Figure 3. Effect of changes in pitch bearing stiffness on trim of two-TEF rotor. Outboard flap collective control. 
to Fig. 3a) are required since the flap is located further inboard and therefore operating in a lower dynamic pressure environment. On the other hand, the more outboard location of the cyclic flap results in smaller longitudinal cyclic deflections at high advance ratios (compare Figures $3 \mathrm{~b}$ and $4 \mathrm{~b}$ ), and reduces the lateral cyclic control throughout the flight speed range examined (compare Figures $3 \mathrm{c}$ and 4c). These deflection changes produce an overall decrease in the cyclic control flap deflections, $\delta_{1}$ (compare Figures $3 \mathrm{~d}$ and $4 \mathrm{~d}$ ), and prevent the divergent behavior of $\delta_{1}$ amplitude at higher advance ratios for moderate/high pitch bearing stiffness. The trends in vehicle attitude are not affected by interchanging the TEF control functions, but compared to Figures 3(e and f), Figures $4(\mathrm{e}$ and $\mathrm{f})$ do indicate a greater sensitivity in vehicle pitch and roll to changes in pitch bearing stiffness.

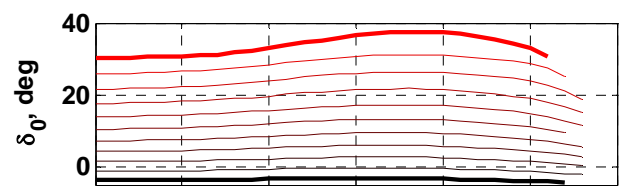

(a) Collective control
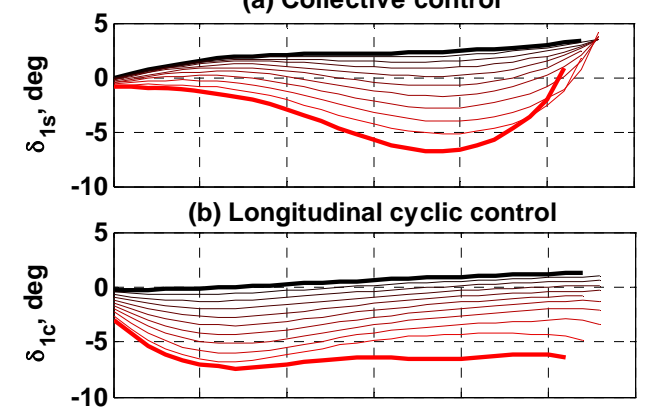

(c) Lateral cyclc control

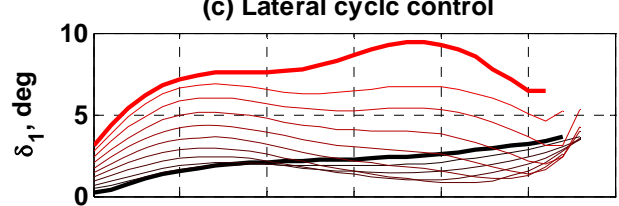

(d) Cyclic control amplitude

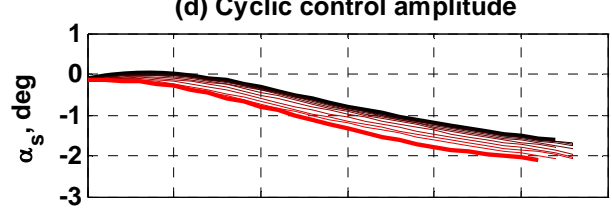

(e) Fuselage pitch

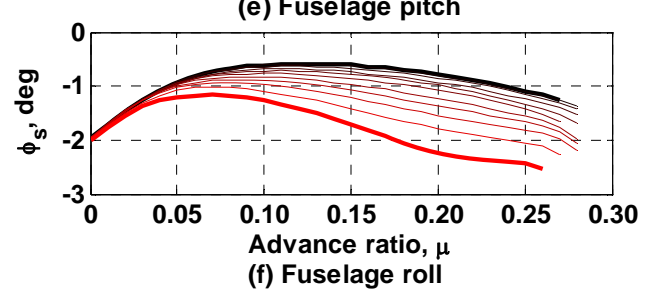

Figure 4. Effect of changes in pitch bearing stiffness on trim. Outboard flap cyclic control.

\section{Blade pitch index}

The effect of changes in blade pitch index, $\theta_{\mathrm{p}}$, on TEF flap deflections and vehicle attitude is presented in Figure 5. For this study the inboard TEF provides collective control and the outboard TEF provides cyclic control. The pitch index, as measured at the blade root, is varied from 10 to 30 degrees. Increasing the pitch index results in more positive collective control flap settings, $\delta_{0}$ (Fig. 5a). To minimize the collective controls, a pitch index in the range of 20 to 22 degrees is optimal. The amplitude of longitudinal cyclic control, $\delta_{1 \mathrm{~s}}$, reduces as the pitch index is increased, while the lateral cyclic control, $\delta_{1 \mathrm{c}}$, appears to be insensitive to the variation in the pitch index, a trend also noted in singleTEF rotors ${ }^{3}$. Based on these observations, a higher pitch index is beneficial for reducing cyclic TEF controls, as substantiated by Figure $5 \mathrm{~d}$, the cyclic

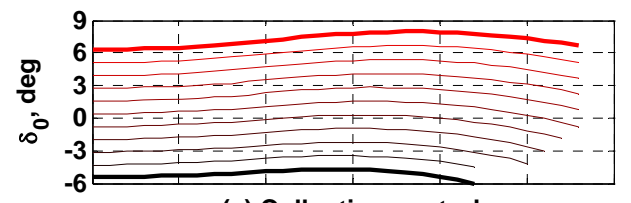

(a) Collective control

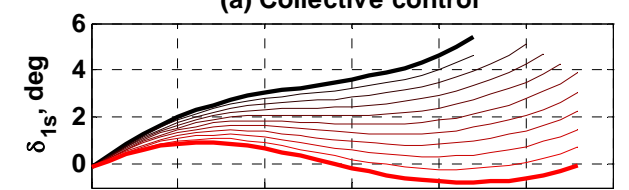

(b) Longitudinal cyclic control

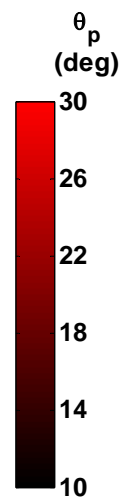

(d) Cyclic control amplitude

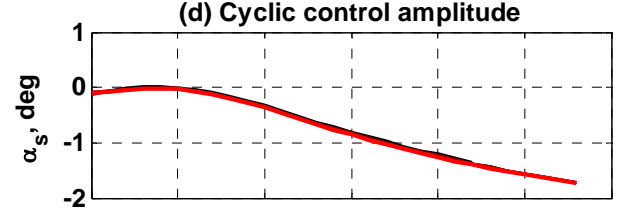

(e) Fuselage pitch

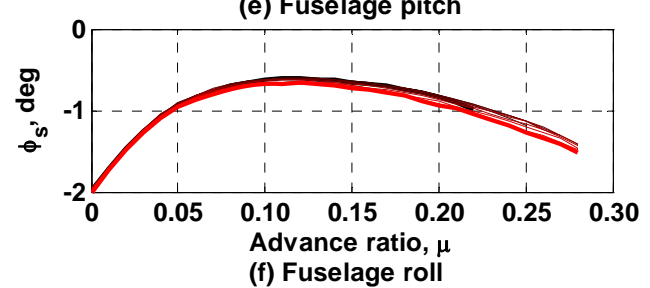

Figure 5. Effect of changes in pitch index on trim of a two-TEF rotor. Outboard flap cyclic control. 
control amplitude. Figures 5(e-f) indicate that the pitch index has a limited effect on the vehicle attitude.

At low blade pitch index values (less than 20 degrees), the comprehensive analysis was incapable of identifying a trimmed solution for the highest flight speeds. The mechanism linking small pitch index angles to slower maximum flight speeds can be surmised from Figure 6 . This figure presents sectional lift coefficient distribution on a rotor disk at an advance ratio of 0.22 (the maximum trimmed flight speed for $\theta_{p}$ of 10 degrees) for two swashplateless designs: $\theta_{\mathrm{p}}=10$ degrees (Fig. 6a) and $\theta_{\mathrm{p}}=30$ degrees (Fig. 6b). For the 10 degree pitch index case, the collective control TEF is deflected flap-up (see Fig. 5a). This negative flap deflection produces a positive pitching moment to pitch the blades nose-up, but locally reduces the lift coefficient. To compensate for this local reduction in lift, the blades must operate at higher lift coefficients, resulting in the onset of stall at a lower flight speed compared to the higher pitch index

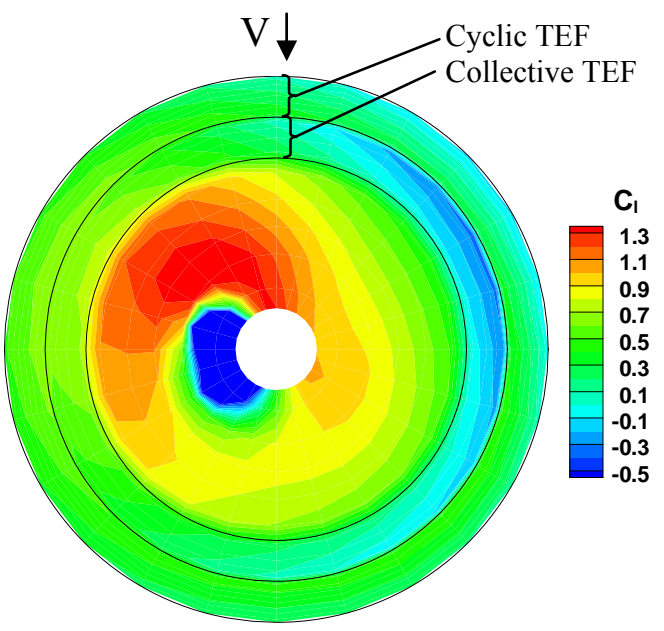

(a) Pitch index: 10 degrees

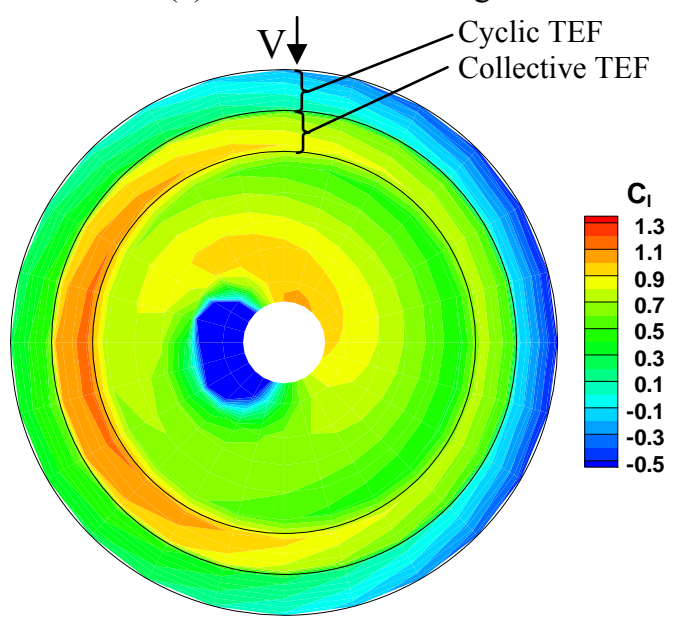

(b) Pitch index: 30 degrees

Figure 6. Effect of pitch index on section lift coefficient. Two-TEF rotor, outboard flap cyclic control, $\mu=0.22$. case. The sectional lift distribution for the 30 degree pitch index case, Figure $6 \mathrm{~b}$, is significantly different from Figure $6 a$ even though the rotor operates at the same flight speed. In order to produce the proper amount of rotor thrust, the blade collective pitch must be reduced relative to the pitch index. To accomplish this collective pitch change, the collective TEFs are deflected down (see Fig. 5a), simultaneously producing a nose-down pitching moment and an increase in the local lift coefficient. This local increase in lift, reduces the amount of lift that the rest of the blade must produce, particularly inboard of the collective TEF (compare Figures 6a and b). This relationship between the blade pitch index and the lift distribution illustrates the need for additional care in the selection of the blade pitch index.

Figure 7 presents the change in trim schedule due to blade pitch index variation for a two-TEF swashplateless rotor where the outboard flap provides
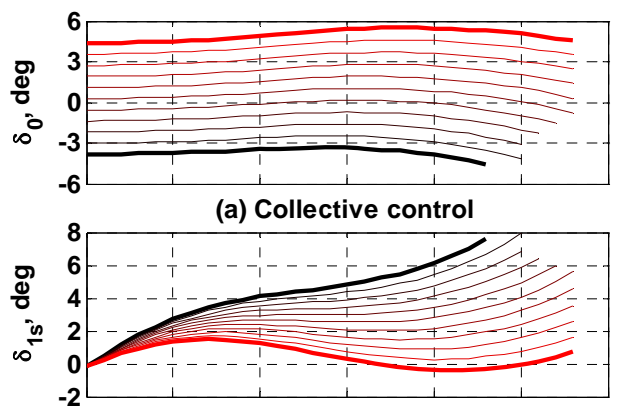

(b) Longitudinal cyclic control

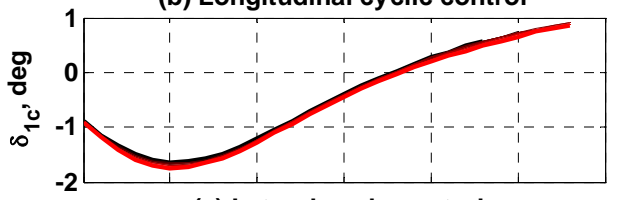

(c) Lateral cyclc control

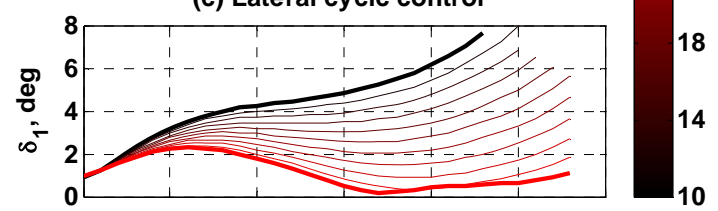

(d) Cyclic control amplitude

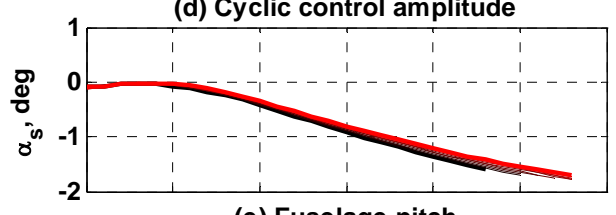

(e) Fuselage pitch

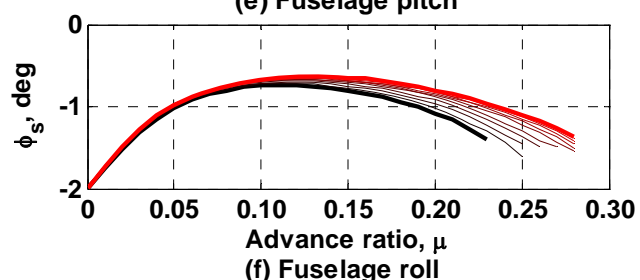

Figure 7. Effect of changes in pitch index on trim of a two-TEF rotor. Outboard flap collective control. 
collective control and the inboard flap provides cyclic control. The majority of the trends are similar to those presented in Figure 5. The interchange of TEF control function results in the collective flap operating in a higher dynamic pressure environment (compared to the design presented in Fig. 5a), therefore requiring smaller collective flap deflections to trim the vehicle. The TEF providing cyclic control is now operating at a lower dynamic pressure due to its inboard location, requiring larger TEF deflections to trim the rotor (compare Figures 7(b-d) and 5(b-d)). In this distribution of TEF control functions, the fuselage roll angle, Fig. 7f, is more sensitive to the blade pitch index change compared to the design where the outboard TEF provides cyclic control. The fuselage roll is primarily a function of tail rotor thrust and therefore an indicator of the main rotor torque and power. Comparing Figures $5 \mathrm{f}$ and $7 \mathrm{f}$ indicates that the outboard collective TEF design

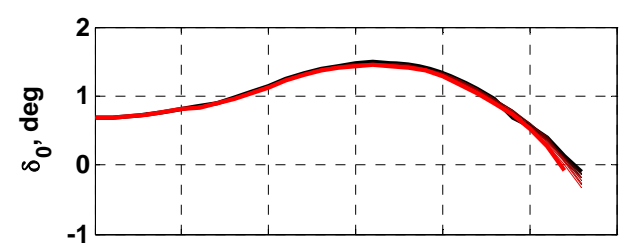

(a) Collective control

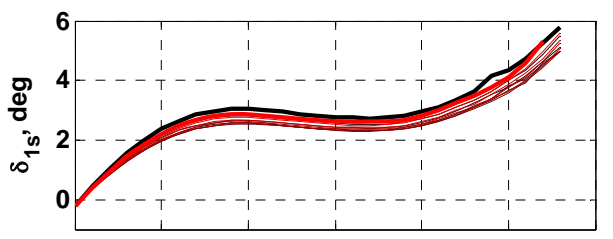

(b) Longitudinal cyclic control

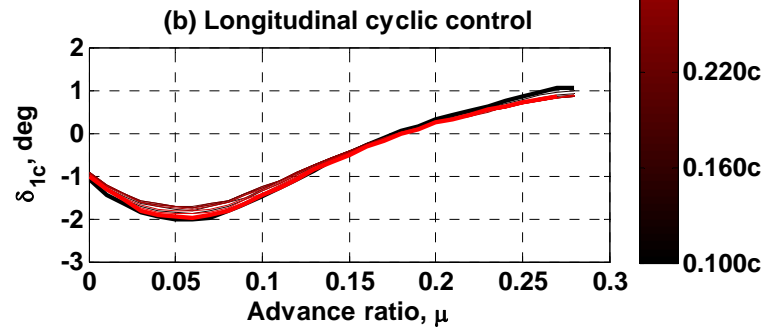

(c) Lateral cyclic control

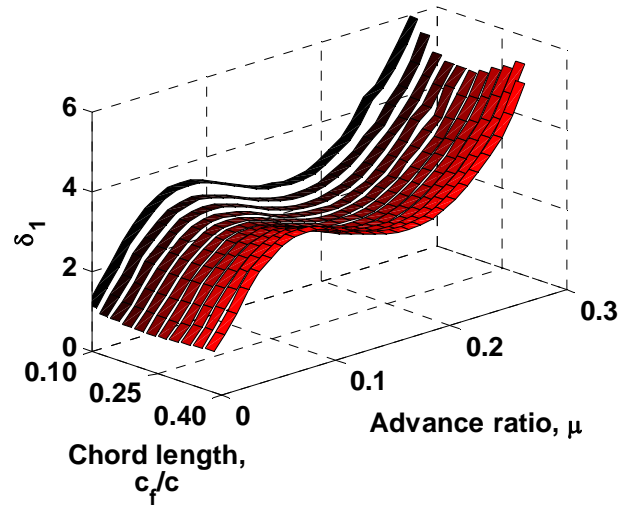

(d) Cyclc control amplitude

Figure 8. Effect of changes in inboard flap chord length on trim of two-TEF rotor. Inboard flap cyclic control. may require more rotor power to achieve trim for the same flight conditions as compared to the inboard collective flap design.

\section{Flap chord length}

The effect of changing the chordwise extent of the inboard flap on the cyclic and collective TEF deflections is presented in Figures 8 and 9. The flap chord is varied from 10 to 40 percent of the blade chord. The TEF trim schedules presented in Figure 8 are for the case where the cyclic control is provided by the inboard TEF. For all advance ratios, the cyclic deflections initially decrease as the flap chord is increased, reach a minimum between $0.2 \mathrm{c}$ and $0.25 \mathrm{c}$ and then begin to increase again. This observation is presented more clearly in Figure 8d using a perspective view. The outboard (collective) TEF deflections are

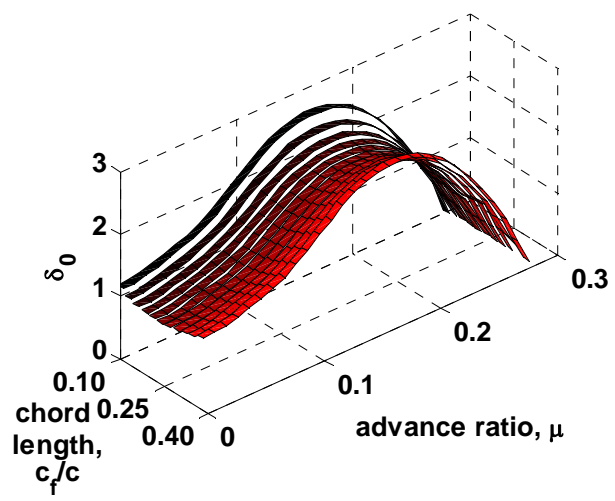

(a) Collective control

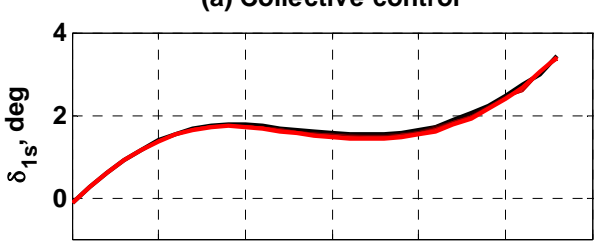

(b) Longitudinal cyclic control

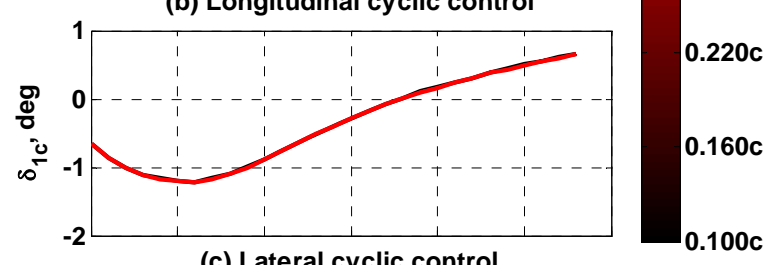

(c) Lateral cyclic control

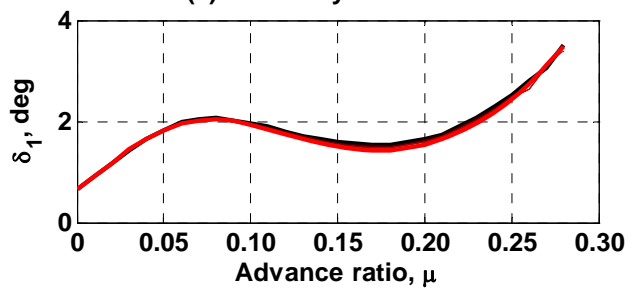

(d) Cyclc control amplitude

Figure 9. Effect of changes in inboard flap chord length on trim of two-TEF rotor. Inboard flap collective control. 
also affected by changes in the inboard TEF chord length. At advance ratios greater than 0.1, increasing the inboard TEF chord length appears to produce a small, negative change in the collective deflection of the outboard flap (Fig. 8a).

Trailing edge flap chord length has a similar effect on flap deflections if the inboard TEF provides collective control (Fig. 9). TEF collective deflections for the inboard flap are minimized in the $0.2 \mathrm{c}$ to $0.26 \mathrm{c}$ range throughout the flight speed range examined. Once again the outboard TEF deflections indicate a limited coupling with the inboard TEF chord length (Figures $9(\mathrm{~b}$ and $\mathrm{d})$ ). This coupling affects $\delta_{1 \mathrm{~s}}$ deflections and tends to decrease the overall cyclic TEF deflection requirement in the 0.1 to 0.25 advance ratio range.

Similar trends were observed when the chord of the outboard flap was varied. For brevity, these results are not presented.

\section{Flap radial location}

The radial location of the TEFs has a significant impact on flap deflection. Figures 10 and 11 present the sensitivity of the cyclic and collective TEF control to

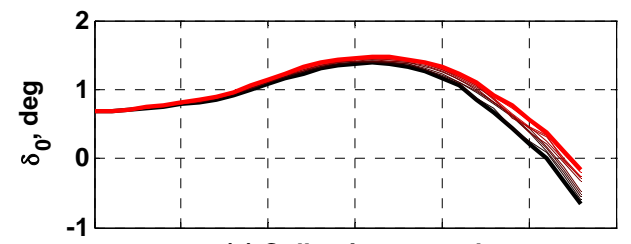

(a) Collective control

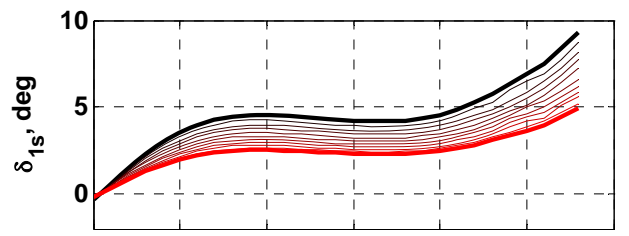

(b) Longitudinal cyclic control

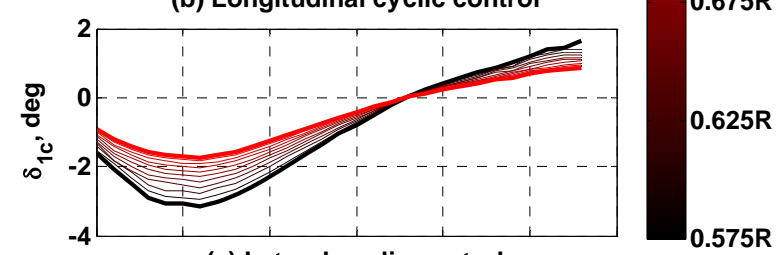

(c) Lateral cyclic control

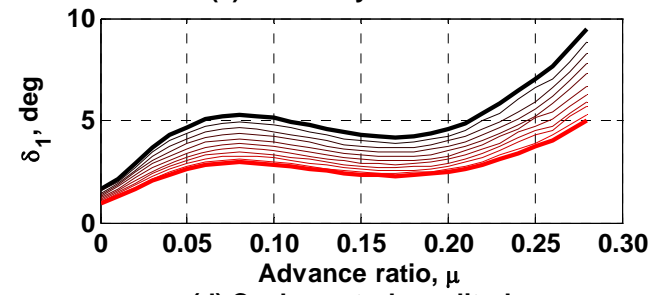

(d) Cyclc control amplitude

Figure 10. Effect of changes in inboard flap location on trim of two-TEF rotor. Inboard flap cyclic control. the inboard flap location as the center of a $0.15 \mathrm{R}$ span flap is moved from $0.575 \mathrm{R}$ to $0.775 \mathrm{R}$. For these studies, the center of the outboard flap, also $0.15 \mathrm{R}$ span, is maintained at $0.925 \mathrm{R}$. The case where the inboard TEF is used for cyclic control, Figure 10, indicates that as the inboard flap is moved radially outward to a higher dynamic pressure environment, the cyclic control requirements are reduced significantly. Simultaneously, the collective (outboard) flap deflections (Fig. 10a) become more positive, resulting in increased $\delta_{0}$ deflections for flight speeds up to $\mu=0.26$. Likewise, if the inboard flap is used for collective control, Figure 11, the collective control requirements are reduced, but small increases in cyclic flap deflections are noted.

The effect of changes in the outboard TEF radial location on cyclic and collective control is presented in Figures 12 and 13. The outboard TEF location is varied over a $0.20 \mathrm{R}$ range, where the center of this flap moves from $0.725 \mathrm{R}$ to $0.925 \mathrm{R}$. The center of the inboard TEF is located at $0.575 \mathrm{R}$. In Figure 12 the outboard TEF is employed for collective control. As the outboard TEF is moved from $0.725 \mathrm{R}$ to $0.925 \mathrm{R}, \delta_{\mathrm{o}}$ is reduced throughout the examined flight envelope. Moving the outboard TEF towards the blade tip increases $\delta_{1 \mathrm{~s}}$ minimally

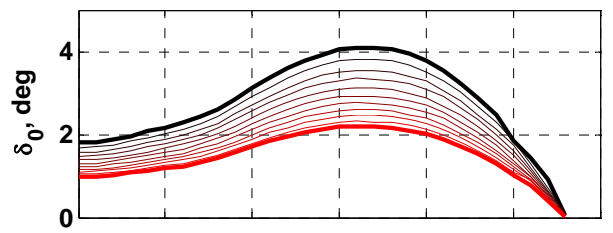

(a) Collective control

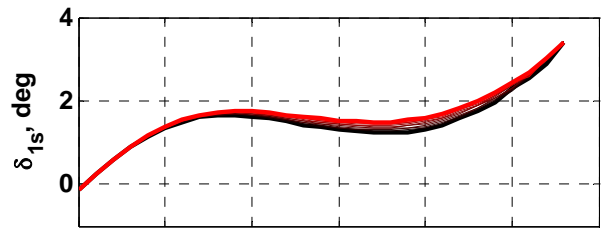

(b) Longitudinal cyclic control
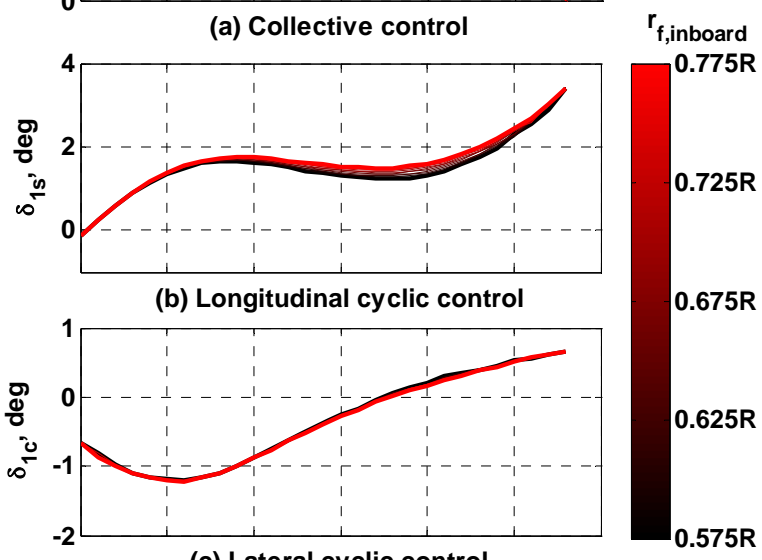

(c) Lateral cyclic control

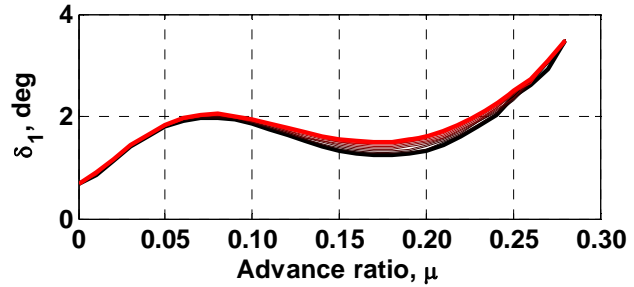

(d) Cyclc control amplitude

Figure 11. Effect of changes in inboard flap location on trim of two-TEF rotor. Inboard flap collective control. 
resulting in a small increase in the cyclic deflection magnitude, $\delta_{1}$, of the inboard flap (Figures 12(b and d)). Similarly, if the outboard TEF is used for cyclic control, Figure 13, the cyclic control requirements are reduced by moving the outboard TEF towards the blade tip. Simultaneously, the collective TEF deflections became more positive, or flap-down, particularly at higher flight speeds.

These parametric studies confirm that both TEFs need to be as far outboard on the blade as possible in order to minimize flap deflections. Since one flap needs to be placed inboard of the other, a criteria needs to be identified as to which control function should be dedicated to each TEF. Another possibility that could be explored is using a leading edge device for one of the control functions. This concept would allow both devices to be located near the tip of the blade, but its investigation is beyond the scope of this paper.

\section{Flap span}

The span of a TEF is another parameter capable of producing significant changes in TEF displacement. Figures 14 and 15 present TEF deflection schedules for

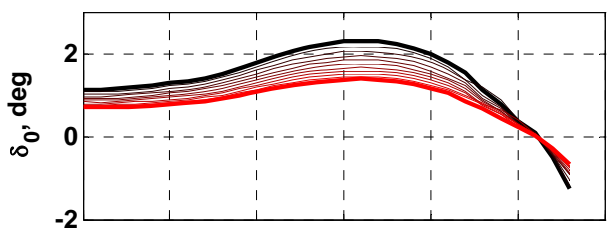

(a) Collective control

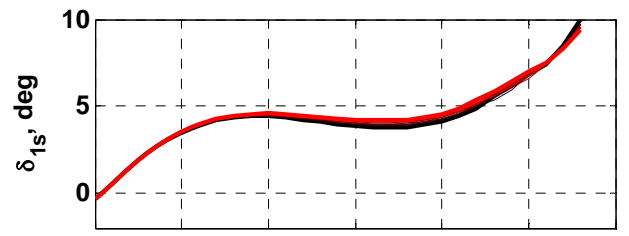

(b) Longitudinal cyclic control

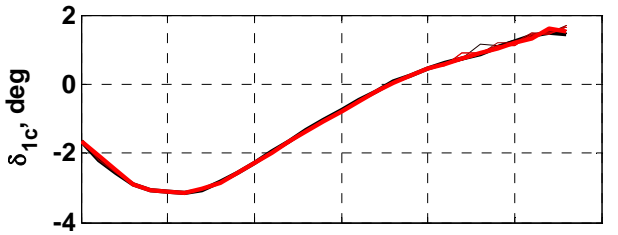

(c) Lateral cyclic control

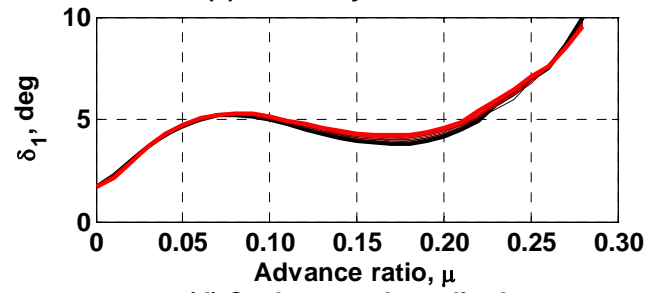

(d) Cyclc control amplitude

Figure 12. Effect of changes in outboard flap location on trim of two-TEF rotor. Outboard flap collective control.

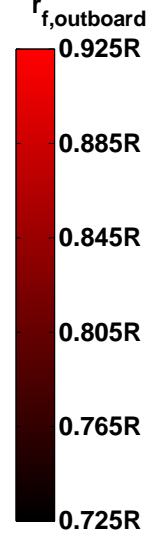

swashplateless rotor designs where the inboard TEF span is varied from $0.1 \mathrm{R}$ to $0.35 \mathrm{R}$. This TEF is centered at $0.675 \mathrm{R}$ while the outboard TEF is located at $0.925 \mathrm{R}$. In Figure 14 the inboard TEF provides cyclic control and in Figure 15 it provides collective control. In both control scenarios, increasing the flap span decreased the required inboard TEF deflections, but did not affect the deflections of the outboard TEF.

Figures 16 and 17 present the TEF deflection schedules for swashplateless rotors where the outboard TEF span is varied from $0.1 \mathrm{R}$ to $0.35 \mathrm{R}$. The center of the outboard TEF is held constant at $0.825 \mathrm{R}$ while the center of the inboard TEF is located at $0.575 \mathrm{R}$. Increasing the outboard TEF span, where the outboard TEF provides cyclic control, significantly reduces the required cyclic TEF deflections (Fig. 16). A similar observation can be made for collective deflections when the outboard TEF provides collective control (Fig. 17).

While increasing the outboard TEF span can reduce the outboard flap deflection requirements, it forces the inboard flap to be located further inboard on the rotor blade. Moving the inboard TEF closer to the hub requires it to operate in a lower dynamic pressure

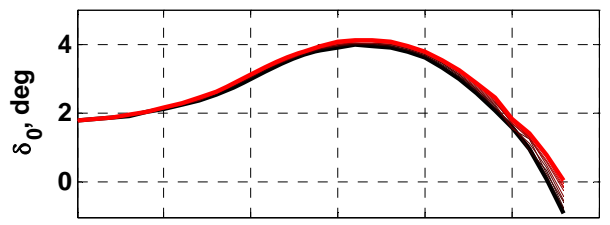

(a) Collective control
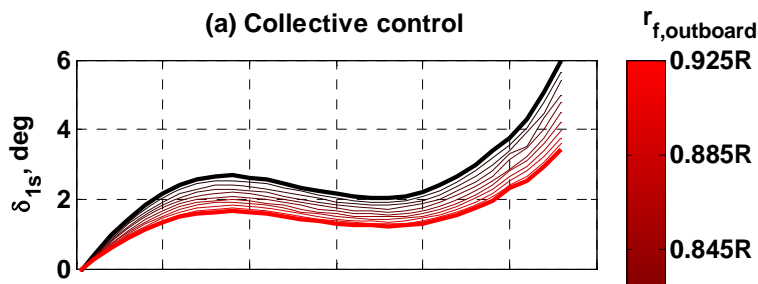

(b) Longitudinal cyclic control

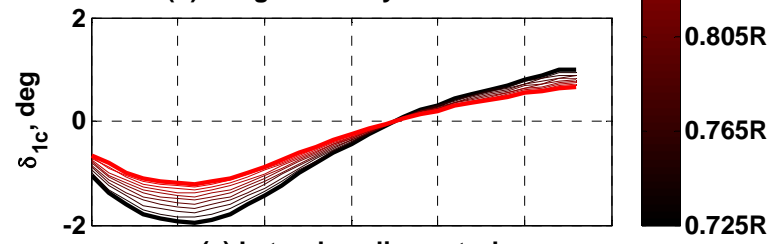

(c) Lateral cyclic control

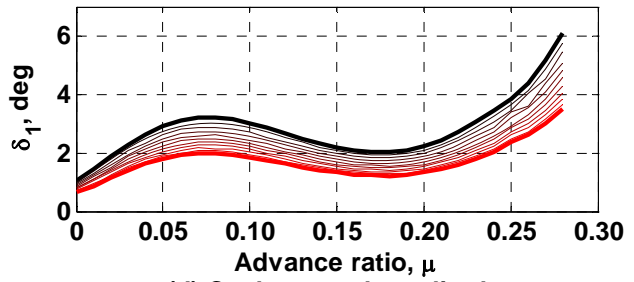

(d) Cyclc control amplitude

Figure 13. Effect of changes in outboard flap location on trim of two-TEF rotor. Outboard flap cyclic control. 
environment, which has been shown to increase TEF deflections. Therefore in a two-TEF swashplateless rotor design, selection of the outer flap span must involve considerations of the inboard flap deflection requirements and actuator capabilities.

\section{Optimal Two-TEF Design}

The single TEF objective function (eq. 1) was modified in order to identify candidate designs for an optimal two-TEF swashplateless rotor. The objective function, presented below, is designed to minimize the maximum amplitude of both the cyclic and the collective TEF deflections within the flight regime considered in this study. In this study the collective TEF deflections, $\delta_{0}$, and the cyclic TEF deflections, $\delta_{1}$, are assumed to be equally important and therefore their weighting factors, $w_{1}$ and $w_{2}$, were set to 1 .

$$
\mathrm{J}_{2}=\max \left(w_{1}\left|\delta_{0}(\mu)\right|+w_{2} \delta_{1}(\mu)\right)
$$

Two optimization studies were conducted - one for each TEF control configuration. As an additional step, the optimum designs were adjusted based on the observation made in the single-TEF optimization study

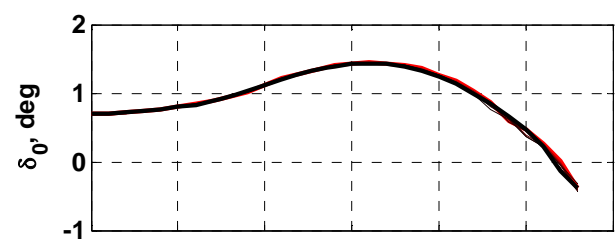

(a) Collective control

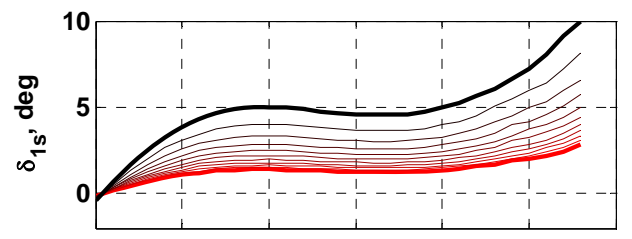

(b) Longitudinal cyclic control

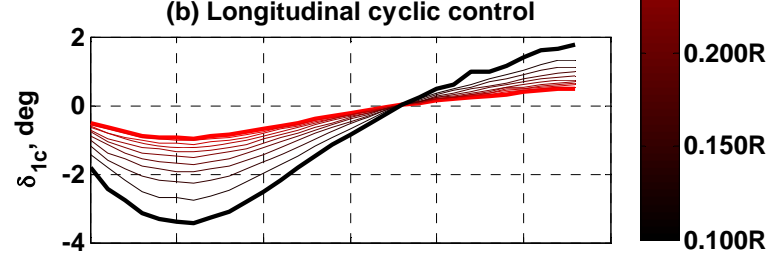

(c) Lateral cyclic control

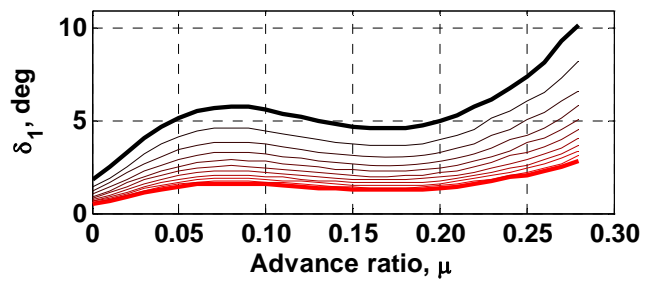

(d) Cyclc control amplitude

Figure 14. Effect of changes in inboard flap span on trim of two-TEF rotor. Inboard flap cyclic control.
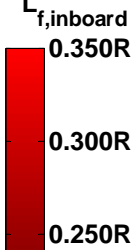

that the collective control should not be deflected at the maximum flight speed. As has been presented, the collective TEF deflections can be adjusted by increasing either the pitch bearing stiffness or the blade pitch index. Since a higher pitch bearing stiffness is not desirable because it increases the magnitude of both cyclic and collective TEF deflections, the blade pitch index is adjusted to minimize the collective TEF deflections at the maximum advance ratio considered in this study, $\mu=0.28$.

\section{TEF deflections}

A total of four candidate designs were identified for a two-TEF swashplateless rotor using the objective function, $\mathrm{J}_{2}$, with and without additional blade pitch index adjustments. The optimized parameters for these four designs are listed in Table 6 and the TEF deflection schedules for trimmed, level flight are presented in Figure 18. Using the objective function, $\mathrm{J}_{2}$, two rotor designs were identified: one with outboard TEF providing cyclic control (presented in red) and one with the outboard flap providing collective control (presented in blue). The solid lines represent designs where the overall flap deflections are minimized and the dashed
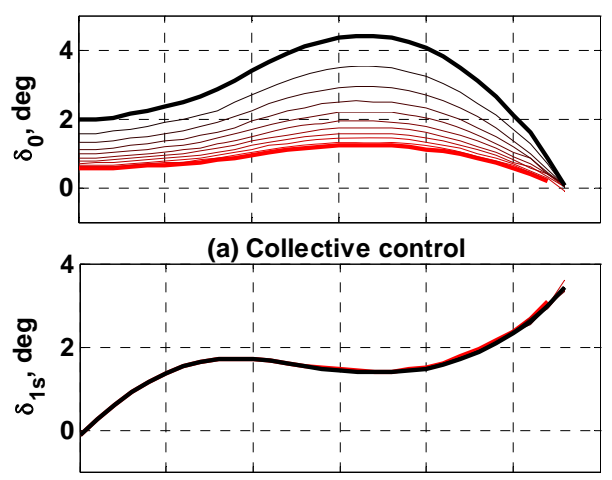

$\mathbf{L}_{\mathbf{f} \text {,inboard }}$

(b) Longitudinal cyclic control

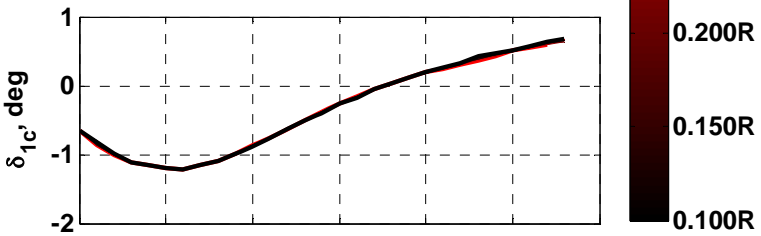

(c) Lateral cyclic control

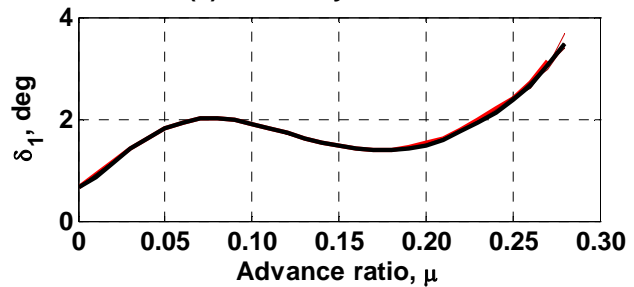

(d) Cyclc control amplitude

Figure 15. Effect of changes in inboard flap span on trim of two-TEF rotor. Inboard flap collective control. 


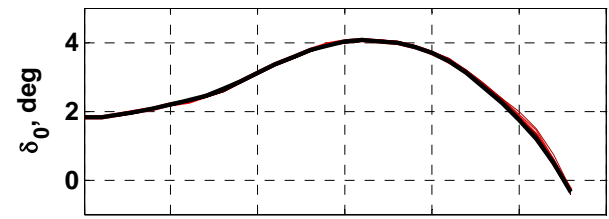

(a) Collective control

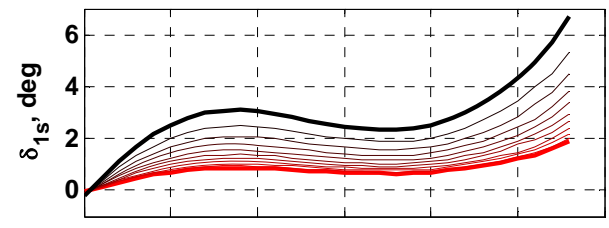

(b) Longitudinal cyclic control

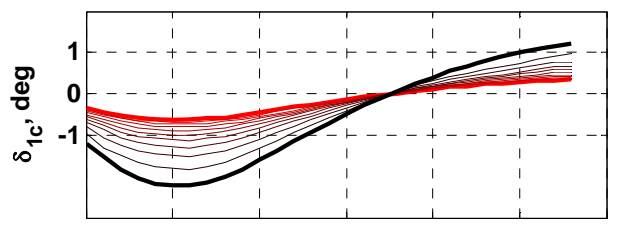

(c) Lateral cyclic control

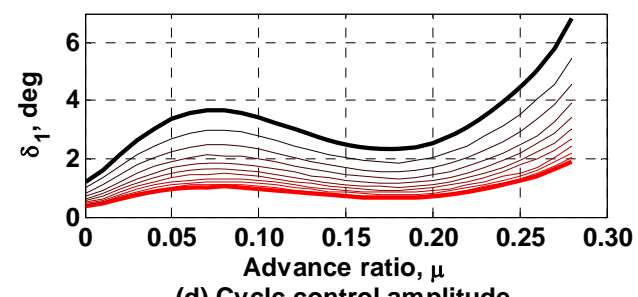

(d) Cyclc control amplitude

Figure 16. Effect of changes in outboard flap span on trim of two-TEF rotor. Outboard flap cyclic control.

lines represent designs with an adjusted blade pitch index to minimize the collective deflections at an advance ratio of 0.28 (labeled $\mathrm{J}_{2}+\theta_{\mathrm{p}}$ ).

Rotor designs where the outboard TEF provides collective control require lower collective TEF deflections to trim the vehicle than the designs where the outboard TEF provides cyclic control, because the outboard TEF operates in a higher dynamic pressure environment (Fig. 18a). The designs where $\delta_{0}$ is minimized at an advance ratio of 0.28 use more positive collective TEF deflections to trim the vehicle than the designs identified with objective function $J_{2}$. Regardless of the advance ratio, all four designs require significantly lower collective TEF deflections than the overall TEF deflections $\left(\delta_{\mathrm{f}}\right)$ for the single-TEF rotor, represented by a dashed green line.

The cyclic TEF deflection components and amplitudes are presented in Figures 18(b-d). The outboard TEF cyclic control designs require smaller cyclic TEF deflections than the inboard cyclic TEF designs. Compared to the $\delta_{\mathrm{f}}$ for single-TEF rotor design, presented in green in Figure 18d, cyclic TEF deflections for the two-TEF rotor are significantly lower throughout

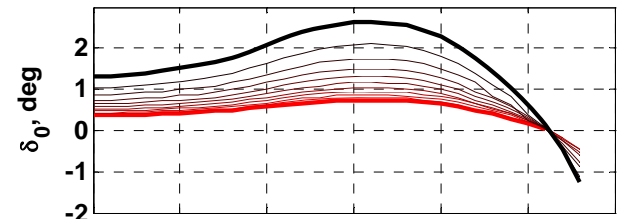

(a) Collective control

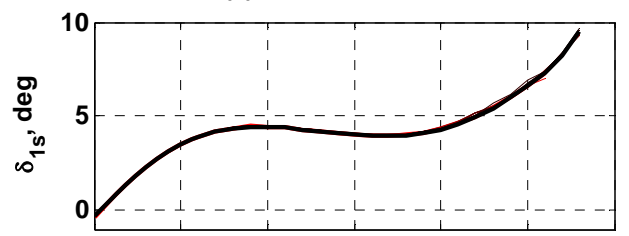

$L_{\text {f,outboard }}$

(b) Longitudinal cyclic control

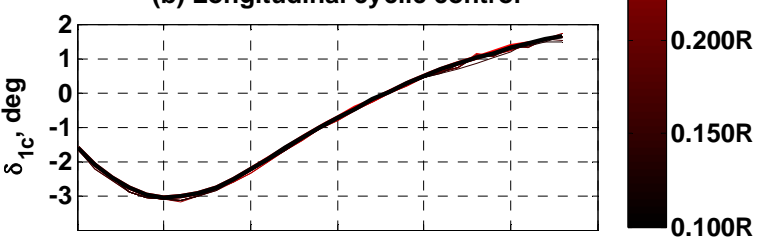

(c) Lateral cyclic control

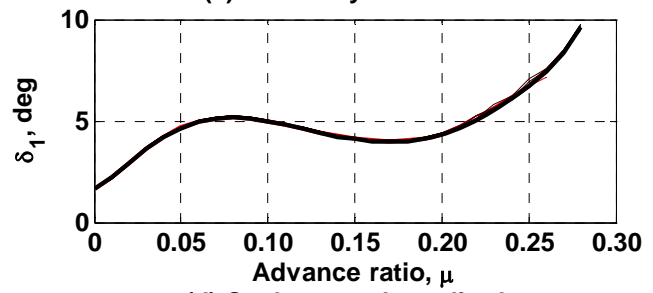

(d) Cyclc control amplitude

Figure 17. Effect of changes in outboard flap span on trim of two-TEF rotor. Outboard flap collective control.

Table 6. Optimized two-TEF swashplateless rotor design parameters.

\begin{tabular}{|l|c|c|c|c|}
\hline $\begin{array}{l}\text { Outboard TEF } \\
\text { control function }\end{array}$ & $\delta_{1}$ & $\delta_{1}$ & $\delta_{0}$ & $\delta_{0}$ \\
\hline Objective function & $\mathrm{J}_{2}$ & $\mathrm{~J}_{2}+\theta_{\mathrm{p}}$ & $\mathrm{J}_{2}$ & $\mathrm{~J}_{2}+\theta_{\mathrm{p}}$ \\
\hline $\begin{array}{l}\text { Pitch bearing } \\
\text { stiffness (ft-lb/rad) } \\
\text { [torsion freq.] (/rev) }\end{array}$ & $\begin{array}{c}1161 \\
{[1.38]}\end{array}$ & $\begin{array}{c}1161 \\
{[1.38]}\end{array}$ & $\begin{array}{c}934 \\
{[1.31]}\end{array}$ & $\begin{array}{c}934 \\
{[1.31]}\end{array}$ \\
\hline $\begin{array}{l}\text { Blade pitch } \\
\text { index (deg) }\end{array}$ & 22.3 & 24.3 & 25.8 & 27.8 \\
\hline Inboard TEF chord & $0.235 \mathrm{c}$ & $0.235 \mathrm{c}$ & $0.238 \mathrm{c}$ & $0.238 \mathrm{c}$ \\
\hline Outboard TEF chord & $0.228 \mathrm{c}$ & $0.228 \mathrm{c}$ & $0.205 \mathrm{c}$ & $0.205 \mathrm{c}$ \\
\hline $\begin{array}{l}\text { Radial location of } \\
\text { inboard TEF center }\end{array}$ & $0.775 \mathrm{R}$ & $0.775 \mathrm{R}$ & $0.775 \mathrm{R}$ & $0.775 \mathrm{R}$ \\
\hline $\begin{array}{l}\text { Radial location of } \\
\text { outboard TEF center }\end{array}$ & $0.925 \mathrm{R}$ & $0.925 \mathrm{R}$ & $0.925 \mathrm{R}$ & $0.925 \mathrm{R}$ \\
\hline
\end{tabular}

most of the flight regime. Only near the maximum flight speed do the cyclic TEF deflections approach the amplitude of the single-TEF maximum deflections, since at $\mu=0.28$ the single-TEF rotor $\delta_{\mathrm{f}}$ is almost entirely a function of cyclic control (see Fig. 2). 
The nose-up adjustment of the blade pitch index reduces the amplitude of the cyclic TEF deflections for most flight speeds. This change in the blade pitch index is most beneficial in high speed flight. For the outboard cyclic TEF design, this adjustment reduces the cyclic TEF deflections by 0.75 degrees compared to the singleTEF deflections at $\mu=0.28$. Based on trends in Figure 5, further reductions in cyclic deflections are possible by further increases in the pitch index, but at a cost of larger collective deflections.

\section{Total power}

The TEF drag model incorporated in this analysis provides the opportunity to estimate the changes in the total vehicle power due to the switch from swashplatebased rotor control to single-TEF and two-TEF rotor control. The relative difference in total power, when compared to a conventionally controlled rotor, for each swashplateless rotor design is presented in Figure 19. All swashplateless rotors exhibit higher total vehicle power requirements than the conventionally controlled rotor. Compared to the single-TEF swashplateless design, the two-TEF designs' power requirements are not substantially different. At the highest advance ratios the outboard cyclic TEF design requires less power than the single-TEF design. Adjusting the blade pitch index, design $\mathbf{J}_{2}+\theta_{\mathrm{p}}$, slightly increases the power required throughout most of the flight regime as compared to the $\mathrm{J}_{2}$ optimized designs, but a beneficial effect on power is observed at high advance ratios.

These results do not reflect the potential reductions in parasite power gained by simplifying the rotor hub. Therefore the net change in total power due to swashplateless rotor control may be negligible or even favorable ${ }^{5}$. Also, the TEF drag model used in this study is simplistic, with many assumptions. While the general trends are likely correct, analysis with more sophisticated aerodynamic models should be performed to better quantify flap deflections and power requirements of a two-TEF swashplateless rotor.

\section{Maneuvering flight}

Simulations of turn maneuvers were performed to compare the influence of the single- and two-TEF swashplateless rotor designs on TEF deflection requirements. Constant turn rate maneuvers ranging from negative (turn-left) to positive (turn-right) turn rates were examined. The trimmed TEF deflections are provided in Figures 20 and 21 for turning flight at advance ratios of 0.2 and 0.25 , respectively. The trends in TEF deflections for the two flight speeds are similar, although at the higher flight speed the range of turn

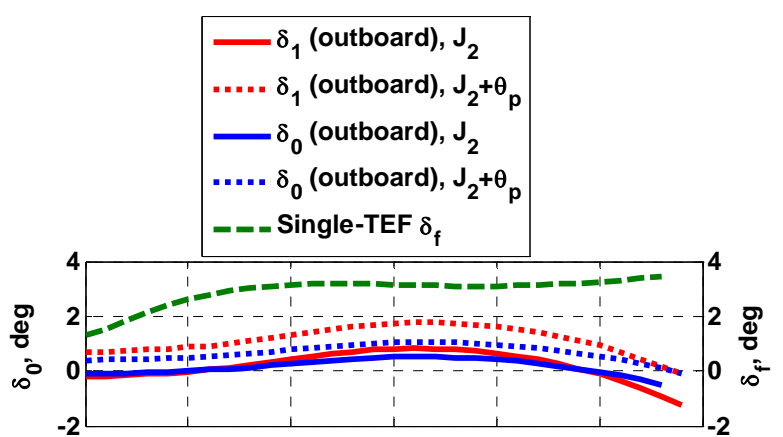

(a) Collective control

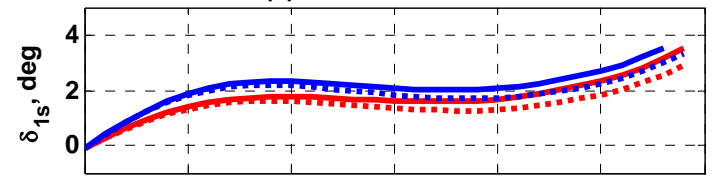

(b) Lateral cyclic control

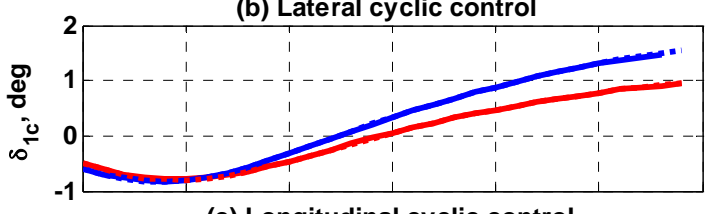

(c) Longitudinal cyclic control

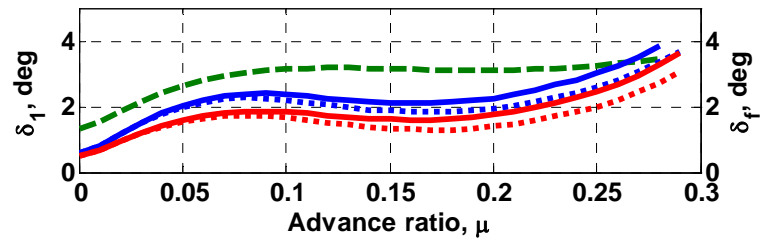

(d) Cyclic control amplitude

Figure 18. Control schedule for two-TEF swashplateless rotor designs as a function of flight speed.

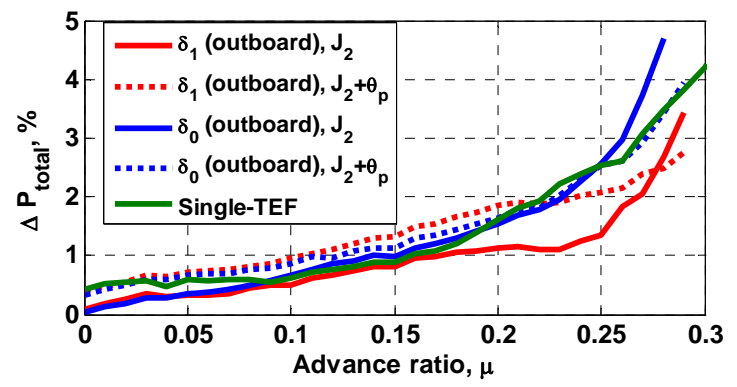

Figure 19. Percent change in total power for single- and two-TEF swashplateless rotor designs as a function of flight speed compared to swashplate controlled rotor.

rates at which trimmed flight is achieved is more limited.

The collective control deflections, Figures 20a and 21a, become more negative as the turn rate is increased in order to produce more rotor thrust. The optimized designs require the largest negative collective flap deflections while the designs with the pitch index adjustment require the largest positive flap deflections. Collective flap deflection trends for all two-TEF rotors 
are similar to $\delta_{\mathrm{o}}$ of the single-TEF rotor (solid green line), but their deflections are significantly smaller when compared to the overall flap deflection $\left(\delta_{\mathrm{f}}\right)$ of the singleTEF rotor (dashed green line).

The cyclic flap controls are provided in Figures 20(b-d) and 21(b-d). As expected, the amplitudes of the cyclic flap deflections, $\delta_{1}$, are larger for the outboard TEF collective control designs (blue) than the outboard TEF cyclic control designs (red). At high turn rates the outboard TEF collective control designs require as large or larger cyclic deflections than the overall deflections $\left(\delta_{\mathrm{f}}\right)$ of the single-TEF design (Figures $20 \mathrm{~d}$ and 21d). The pitch index adjustment of the optimized two-TEF designs is shown to lower the cyclic pitch requirements for turning flight. This adjustment contributes to the outboard TEF cyclic control design having the smallest cyclic flap deflections of any of the swashplateless rotor designs.

Figures 20(e-f) and 21(e-f) present the vehicle attitude as a function of turn rate for the two advance ratios. The pitch and roll schedule for a swashplate-controlled rotor is also provided in black for comparison. All the swashplateless rotor designs require pitch and roll angles similar to the conventional rotor in order to navigate the turns, although the conventional swashplate-controlled rotor can be trimmed at higher turn rates. The cause of this difference in maneuverability, whether it is physical or numerical, has not been determined.

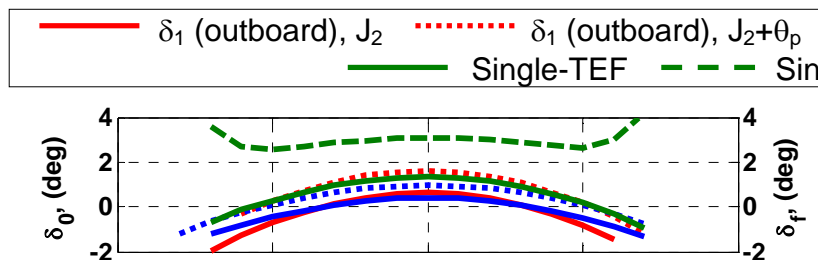

(a) Collective control
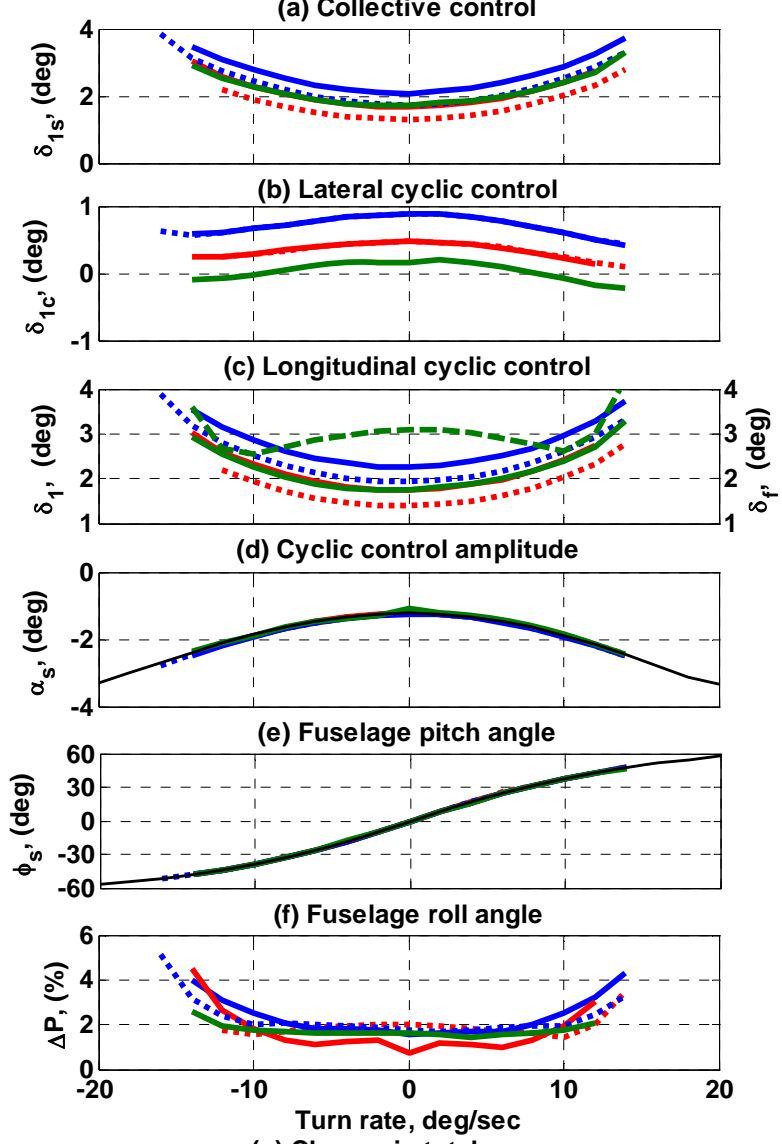

(g) Change in total power

Figure 20. Control schedule and change in power for single- and two-TEF swashplateless rotor designs as a function of turn rate, $\mu=0.2$.
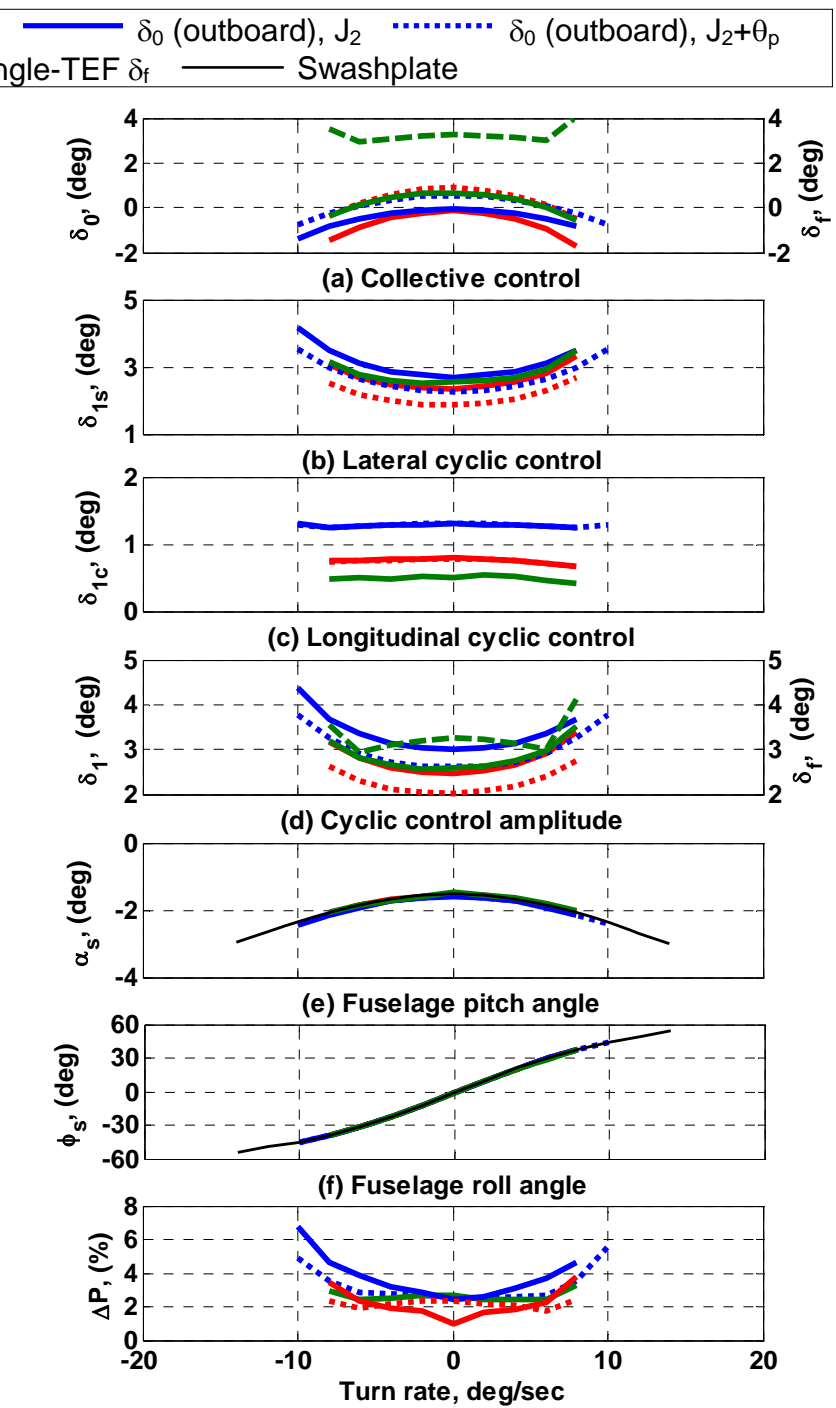

(g) Change in total power

Figure 21. Control schedule and change in power for single- and two-TEF swashplateless rotor designs as a function of turn rate, $\mu=0.25$. 
The difference in total vehicle power for each swashplateless rotor design as compared to a swashplate-controlled rotor at the same flight condition is provided in Figures $20 \mathrm{~g}$ and $21 \mathrm{~g}$. Except at extreme conditions, the single- and two-TEF designs require between 1 and 2 percent more power than the conventional rotor to perform turning maneuvers at an advance ratio of 0.2 and between 2 and 3 percent more power at an advance ratio of 0.25 . It should be noted that at an advance ratio of 0.2 , the outboard TEF cyclic control design (solid red line) requires approximately one percent less power than the outboard TEF collective control design (solid blue line) to perform the same maneuvers. At an advance ratio of 0.25 , the difference in power between these two designs increases, following the trend observed in Figure 19.

\section{Conclusions}

Trailing edge flap (TEF) deflections and power requirements in forward and turning flight were used to assess the merits of a two-TEF swashplateless rotor design compared to a single-TEF design. The results suggest that a two-TEF design in which the outboard TEF provides cyclic control and the inboard TEF provides collective control can reduce the TEF deflection requirements in both steady level and turning flight compared to those for the single-TEF design. Total power requirements for this two-TEF control scheme are unaffected, or even reduced, by the distribution of flight control between two flaps compared to a single flap. Based on these preliminary flap deflection and total power observations, the twoTEF primary flight control concept warrants a more detailed examination.

Key observations from the study of a two-TEF swashplateless rotor design include:

1. The choice of pitch bearing stiffness is extremely important in minimizing flap deflections. Torsionally soft rotor designs, with torsion frequencies between 1.3 and $1.4 / \mathrm{rev}$, were required to minimize TEF deflections.

2. The blade pitch index should be chosen to minimize collective flap deflections at the maximum design speed. While this design strategy does not minimize the overall collective flap deflections, it forces the control system to operate with the collective flap deflected down, producing a positive change in lift throughout the entire flight speed range. This flapproduced lift offloads the rest of the rotor blade resulting in a slight reduction in vehicle total power requirements at the highest advance ratios.

3. Increasing the TEF span reduces the TEF deflections required for trimmed flight. Increasing the span of the outboard TEF can potentially result in larger deflections of the inboard TEF if the inboard TEF is forced to operate closer to the center of rotation of the rotor.

4. Locating the TEFs outboard on the blade reduces the trimmed flight TEF deflections. A small adverse coupling was noted between the two TEFs where moving one TEF towards the blade tip causes a small increase in the deflection requirements of the other TEF.

5. TEF chord should be between $0.2 \mathrm{c}$ and $0.26 \mathrm{c}$ to minimize TEF deflections.

6. At higher advance ratios, the two-TEF swashplateless rotor designs in which the outboard TEF is used for cyclic control require less total vehicle power than designs where the outboard TEF provides collective control.

In the future, more sophisticated models of the rotor and flaps should be employed to further assess this concept. The aerodynamic models used in this study used a simple, linearly varying inflow model and did not include losses due to flap edges and gaps. A fully elastic blade model which includes actuator mass and models actuator dynamics should also be employed and a complete stability assessment should be performed.

\section{Acknowledgements}

The authors would like to thank Dr. Jinwei Shen (NIA) for insightful discussions and Dr. Farhan Gandhi (Pennsylvania State University) for providing the CFDgenerated airfoil tables.

\section{References}

1. Ormiston, R. A. "Aeroelastic considerations for Rotorcraft Primary Control with On-Blade Elevons," Proceedings of the American Helicopter Society $57^{\text {th }}$ Annual Forum, Washington, DC, May 9-11, 2001.

2. Shen, J., Chopra, I. "A parametric Design Study for a Swashplateless Helicopter Rotor with Trailing-Edge Flaps," Proceedings of the American Helicopter Society $58^{\text {th }}$ Annual Forum, Montreal, Canada, June 11-13, 2002.

3. Shen, J., Yang, M., Chopra, I. "Swashplateless Helicopter Rotor with Trailing-Edge Flaps for Flight and Vibration Control," Proceedings of the AIAA/ASME/ASCE/AHS/ASC $45^{\text {th }}$ Structures, Structural Dynamics and Materials Conference, Palm Springs, CA April 19-22, 2004.

4. Duling, C., Gandhi, F., Straub, F. "On Power and Actuation Requirement in Swashplateless Primary Control using Trailing-Edge Flaps," Proceedings of the 
American Helicopter Society $66^{\text {th }}$ Annual Forum, Phoenix, AZ, May 11-13, 2010.

5. Shen, J., Chopra, I., Johnson, W., "Performance of Swashplateless Helicopter with Trailing-Edge Flaps for Primary Flight Control," Journal of the American Helicopter Society, Vol. 55, No. 3, October 2010.

6. Woods, B. K. S., et al. "Design and Testing of a Biologically Inspired Pneumatic Trailing Edge Flap System," Proceedings of the AIAA/ASME/ASCE/AHS/ASC $49^{\text {th }} \quad$ Structures, Structural Dynamics and Materials Conference, Schaumburg, IL, April 7-10, 2008.

7. Falls, J., Datta, A., Chopra, I. "Integrated TrailingEdge Flaps and Servotabs for Helicopter Primary Control," Journal of the American Helicopter Society, Vol. 55, No. 3, July 2010.

8. Viswamurthy, S., and Ganguli, R. "An Optimization Approach to Vibration Reduction in Helicopter Rotors with Multiple Active Trailing Edge Flaps," Aerospace Science and Technology, Vol. 8, No. 3, 2004, pp. 185-194.

9. Kim, J., Smith, E., and Wang, K. "Helicopter Vibration Suppression via Multiple Trailing Edge Flaps Controlled by Resonance Actuation System," Proceedings of the 60th Annual Forum of the American Helicopter Society, Baltimore, MD, June 7-10, 2004.

10. Viswamurthy, S. R., and Ganguli, R. "Using Complete Authority of Multiple Active Trailing Edge
Flaps for Helicopter Vibration Control," Journal of Vibration and Control, Vol. 14, No. 8, 2008, pp. 11751199.

11. Kim, J., Smith, E. Wang, K. "Active load control of an articulated composite rotor blade via dual trailing edge flaps", 44th AIAA/ASME/ASCE/AHS/ASC Structures, Structural Dynamics, and Materials Conference; Norfolk, VA; USA; 7-10 Apr. 2003

12. Gagliardi, A. and Barakos, G. "Analysis and Design of a Flap-Equipped Low-Twist Rotor for Hover" Journal of Aircraft, Vol. 46, No. 1, January-February 2009

13. Johnson, W. CAMRAD II, Comprehensive Analytical Model of Rotorcraft Aerodynamics and Dynamics, Johnson Aeronautics, Palo Alto, California, 1994.

14. Theodorsen, T., and Garrick, I. "Nonstationary Flow About a Wing-Aileron-Tab Combination Including Aerodynamic Balance," NACA Technical Report no. 736, 1942.

15. Duling, C., et al. "Analysis of CFD Predictions for the SC-1094R8 Airfoil with a Trailing Edge Flap," Submitted to the Journal of Aircraft, March 2009.

16. Wei, F., "Design of Soft Torsion Rotor Systems at Kaman Aerospace Corporation," Proceedings of the 58th Annual Forum of the American Helicopter Society, Montreal, Canada, June 11-13, 2002. 